\title{
Inhalation Vapor, Solution Dosage Form
}

National Cancer Institute

\section{Source}

National Cancer Institute. Inhalation Vapor, Solution Dosage Form. NCI Thesaurus. Code C149590.

Liquid preparation consisting of a solution intended for generation of vapor to be inhaled to obtain a local effect. The vapor is usually generated by adding the solution to hot water. 